\title{
Fenômeno e corporalidade em Leibniz
}

\author{
Luis C ésar Guimarães O liva
}

Universidade de São Paulo

resumo 0 problema da corporalidade em Leibniz se vincula necessariamente à discussão sobre 0 estatuto da matéria em uma Metafísica cuja base são as mônadas imateriais. Veremos que, neste contexto, o material deverá ser fenomênico, mas nem por isso ilusório. 0 objetivo deste trabalho é mostrar como o campo fenomênico, cujo caso exemplar é 0 corpo, pode ganhar um suporte metafísico e racionalmente justificado, constituindo o que Leibniz chama de fenômenos bem fundados. Para tal, deverá ser feito um exame cuidadoso da natureza das Forças no pensamento leibniziano e de como elas apresentam o vínculo procurado entre Física e Metafísica.

palavras - chave Leibniz - corpo - fenômeno - matéria - mônada - força

A compreensão da corporalidade em Leibniz passa necessariamente pela exposição de suas doutrinas a respeito da matéria e das forças, dado que a extensão, se entendida cartesianamente como a essência geométrica dos corpos, é totalmente incapaz de apontar para algo de real.A busca metafísica por esta unidade última, a substância, traz como efeito colateral para a Física a exclusão da extensão cartesiana por ser algo meramente imaginativo. Divisível ao infinito, tal extensão carece de uma unidade real. De fato, no artigo 12 do D iscurso de $M$ etafísica, antes de explicitar, no artigo seguinte, as consequêencias da noção de substância, Leibniz afirma que a noção de extensão é insuficiente para constituir uma substância corpórea, e que por isso os corpos demandam algo ligado às almas, a forma substancial, mesmo que esta não interfira diretamente na compreensão dos fenômenos.

R ecebido em abril de 2005. A ceito em junho de 2005.

doispontos, Curitiba, São Carlos, vol. 2, n. 1, p.83-99, outubro, 2005 
Tal afirmação, ainda que pouco desenvolvida no D isarso de M etafísica, não passou despercebida ao cartesiano A rnauld. Este reconhecia a ausência de unidade nos compostos corporais, mas não podia aceitar a conseqüência de que os corpos têm formas substanciais. 0 que há, para A rnauld, são agregados mais e mai s organizados até chegar à perfeição do animal-máquina humano, o qual evidentemente é mais uno que um bloco de mármore, sem contudo adquirir a unidade própria das naturezas espirituais. 0 que Arnauld buscava resguardar era 0 dualismo substancial cartesiano, que o comentário leibniziano ferira de morte.

Em sua resposta, Leibniz mantém a crítica fundando-se na ligação necessária entre realidade e unidade. Com efeito, ele sustenta 0 seguinte axioma: 0 que não pode ser verdadeiramente um ser, também não pode ser verdadeiramente um ser. Sendo assim, é inaceitável a hipótese de Arnauld, de que poderia ser da essência do corpo o fato de não ter uma verdadeira unidade. $\mathrm{N}$ esse caso, Leibniz diz que será então da essência do corpo ser um fenômeno, desprovido de toda realidade, como seria um sonho regrado, pois os próprios fenômenos como o arco-íris ou como um monte de pedras seriam totalmente imaginários se não fossem compostos de seres que têm uma verdadeira unidadel. A essência do que é uno por agregação, como o bloco de mármore ou um exército, não é senão uma maneira de ser daqueles seres que os compõem. Se estes, por sua vez, não tivessem um ser verdadeiro, mas fossem também maneiras de ser, sem remeter-se a nenhuma substância como suporte, seriam seres contraditórios, maneiras de ser sem o ser de que são maneiras, ou então meros fenômenos. $D$ aí a necessidade de colocar unidades imateriais mesmo na base da realidade corpórea: A unidade substancial exige um ser completo indivisível, e naturalmente indestrutível, já que sua noção envolve tudo que lhe deve ocorrer, o que não se poderia achar nem na figura, nem no movimento (que envolvem ambos algo de imaginário, como eu poderia demonstrar), mas sim em uma alma ou forma substancial, a exemplo do que se chama eu².

$M$ as se no $D$ iscurso a questão da unidade substancial é quase um resultado da doutrina da noção completa, na M onadologia ela vem na abertura. Como diz Boutroux ${ }^{3}$, a respeito dos parágrafos iniciais do texto, a simplicidade é apresentada por Leibniz como o critério da substancialidade e da existência absoluta.Tudo que se deixa decompor tem existência meramente fenomênica. Por isso, as substâncias simples não podem 
ter partes, nem portanto extensão, sendo deste modo os verdadeiros átomos da natureza.

Está assim afastada a res cogitans cartesiana, mas não a idéia de substância corpórea. Será preciso compreender o que Leibniz entende por isso, já que não há unidades senão as imateriais. C omo almas geram corpos? A pergunta se radicaliza se lembrarmos da afirmação presente nas principais obras do autor: "...Também não há A Imas inteiramente separadas, nem $G$ ênios sem corpos. Separado completamente, só D eus." 4

M as então o que é o corpo? Já dissemos que não consiste na extensão cartesiana, mas também não consistirá apenas na extensão entendida agora leibnizianamente: " $C$ om efeito, ao desdobrar a noção de extensão percebi que é relativa a algo que deve estender-se e significa a difusão, ou seja, a repetição de certa natureza." ${ }^{5} \mathrm{~A}$ relatividade explícita deste conceito coloca imedia tamente a pergunta pelo que se difunde ou estende, já que a extensão, como predicado, não tem sentido desvinculada de tal coisa. R esponderá Leibniz: poderia ser a maleabilidade ou a cor amarela no ouro, ou então a brancura no leite, todas elas qualidades que se difundem em corpos. $0 \mathrm{~s}$ leitores, lembrados da passagem cartesiana do pedaço de cera, questionarão a vinculação destas qualidades passageiras à extensão, mas Leibniz não se incomodará, dado que a extensão não está aqui na função de atributo essencial da substância. Sabemos que apenas algo de natureza imaterial pode ter pretensão à substancialidade, pretensão de que a extensão leibniziana abdica. No entanto, a brancura e a maleabilidade não podem compor o contínuo e isso pode ser um problema: a divisão do ouro ou do leite acarreta a perda daquelas qualidades, levando a extensão leibniziana a um abismo imaginativo tão profundo quanto 0 da cartesiana. 0 que restará então para que a matéria leibniziana não se desvaneça? A resistência. Difundindo-se pelos corpos em geral e permanecendo independentemente das divisões possíveis, a resistência constitui a matéria, dando-Ihe algo para além do que lhe dera D escartes, a força passiva.

A resposta pela matéria, contudo, não é ainda a reclamada resposta pelo corpo: F ormular-seá agora a seguinte pergunta: qual é esta natureza aja difusão constitui o corpo? Já dissemos que uma difusão da resistência constitui a matéria, mas como segundo nossa opinião há algo no corpo diferente da matéria, surge a pergunta acerca de qual é sua natureza. D izemos, por conseguinte, que 
unicamente pode consistir en tó dynamikó, o prinápio ínsito de mudança e de perseverança." 6 Para dar unidade ao múltiplo do corpo, acrescenta- se agora a atividade à matéria (passiva). Força ativa e passiva deverão agora ser compreendidas para que a corporalidade em Leibniz faça sentido. $\mathrm{N}$ ão que estas forças devam apenas agir sobre os corpos. M ais que isso, estas forças deverão constituí-los, já que o real, para Leibniz, não é menos um campo de formas substanciais do que de forças. 0 caráter privilegiado destas para compreender a substancialidade é destacado vivamente pelo autor:... direi, por agora, que a noção de força, ou seja, potência ( que os alemães chamam $\mathrm{K}$ raft e os franceses, force) - a cuja explicação dediquei a ciência espedal da D inâmica - traz muita luz para entender a verdadeira noção de substância. ${ }^{7} \mathrm{E}$ haverá mesmo uma identificação entre força e substância:...a substância mesma das coisas consiste na força de atuar e padecer. 8

A força passiva ou resistência (ou ainda, matéria primeira) divide-se em antitipia e inércia natural. Pela primeira, conhecida também como impenetrabilidade, um corpo não pode ocupar o lugar de outro, a não ser que este Iho ceda. Pela segunda, um corpo jamais sofrerá alteração no seu movimento ou repouso sem que retarde em alguma medida 0 movimento daquele que o empurra. O s corpos só recebem um novo movimento por meio de uma força, logo resistem ao corpo que os pressiona e reduzem a força dele. Isto não ocorreria se o corpo não tivesse em si, além da pura extensão, um princípio de movimento. D aí decorre que a quantidade de força no universo não possa aumentar nem diminuir, já que a redução de força no corpo que empurra corresponde a um crescimento no corpo empurrado (veremos que se trata da força derivativa, pois a primitiva, confundindo-se com a própria mônada, não pode variar).

Por sua vez, a força ativa é dupla: primitiva e derivativa (substancial ou acidental). D iz Leibniz que a força ativa primitiva é a enteléquia ou forma substancial, a qual se junta à matéria ou força passiva para constituir a substância corpórea. Ela é algo análogo a uma alma, atuando sobre um corpo orgânico que, sem ela, reduz-se a um mero agregado: A s potêndias primitivas constituem as substâncias mesmas, e as potências derivativas, ou, se se quiser, as faculdades, são apenas maneiras de ser, que é preaiso derivar das substândas, e não se as deriva da matéria enquanto ela é apenas máquina, isto é, enquanto se considera por abstração apenas o ser incompleto da matéria primeira, ou 0 
puro passivo. Q uanto a isso, penso que estás de acordo, Senhor, que não está no poder de uma pura máquina fazer nascer a percepção, sensação e raz ão. É preciso então que elas nasçam de alguma outra coisa substancial. $Q$ uerer que $D$ eus aja diferentemente e dê às coisas adidentes que não são maneiras de ser ou modificações derivadas das substâncias é recorrer aos milagres. ${ }^{9}$

Q uanto à força derivativa, o excerto acima já aponta para seu caráter modal. $M$ as antes vejamos outro aspecto fundamental: a força derivativa é um conatus. Em oposição à matéria aristotélica, entendida como pura potência e receptividade, bem como à forma aristotélica, atualização completa, a força derivativa envolve um esforço ou tendência para a ação, de tal maneira que, se não houver obstáculo, a ação ocorrerá:...tal potência envolve 0 ato e não persiste como mera faculdade, ainda que nem sempre proceda integralmente a ação a que tende, isto é, sempre que se Ihe opõe um impedimento. ${ }^{10}$ Pode-se dizer que a força derivativa é uma ação infinitesimal, mas nem por isso ela se confunde com a própria ação:....a força derivada difere da ação assim como o instantâneo difere do sucessivo; pois a força se exerce já desde o primeiro instante, enquanto a ação necessita do transcurso do tempo e portanto é 0 produto das forcas pelo tempo, e se percebe em qualquer parte do corpo. ${ }^{11}$

A apresentação é ainda mais clara em uma carta a D eVolder: A força derivativa, entretanto, é o próprio estado presente, na medida em que tende para, ou pré-envolve, o estado seguinte, tal como todo presente está prenhe de futuro. $M$ as o próprio persistente, enquanto envolve todos os eventos, tem força primitiva, de modo que a força primitiva é como a lei da série, e a força derivativa é como a determinação que designa algum termo na série. ${ }^{12} \mathrm{Em}$ vista destas palavras, tendo a concordar com Adams quando este diz, comentando o trecho acima, que neste contexto a força derivativa nada mais é do que a própria força primitiva, na medida em que é ou envolve uma tendência a fazer, no instante, aquilo que a razão da série a determina a fazer. I sto, aliás, vai ao encontro do referido caráter modal da força derivativa, bem como das ações produzidas por ela. A própria variabilidade destas já aponta para 0 caráter de modo, o que logicamente exige algo persistente de que seja a modificação. E tal como a figura é certa limitação ou modificação da força passiva ou massa extensa, assim a força derivativa e a ação motriz é certa modificação, não, sem dúvida, de uma coisa meramente passiva (pois neste caso a modificação ou limite envolveria mais realidade que o que é limitado), mas de algo ativo, isto é, da enteléquia primitiva. 13 
A pergunta que fica, todavia, é como algo puramente espiritual, como a força primitiva, pode modificar-se em algo que se realiza corporalmente, tal como a força derivativa. Se a mônada, absolutamente simples, não tem portas nem janelas, como é possível falar de choque de corpos, onde alguns ganham força, outros perdem, uns ganham movimento, outros mudam de direção?

A primeira resposta é que não há transmissão ou redução de força por ação externa. Q uando uma bola de bilhar bate em outra, esta não é movida pela mesma força da primeira bola. São forças equivalentes, mas diversas, de modo que cada bola se move por sua própria força. C omo já dissemos, as forças em Leibniz nunca são pura potência, mas sempre se atualizam. Logo a força primitiva sempre produz força derivativa e ação, mesmo quando os corpos parecem em repouso. D esse modo, há sempre um movimento interior cuja força produtora pode ser vertida para fora ao cumprir a função de força elástica, a saber: quando o movimento interior é impedido de seguir seu curso normal. Daí que o choque não indique transmissão de forças e movimentos entre os corpos: A gora bem, o choque, quando os corpos se batem, ocorre pela força elástica, donde segue que na verdade os corpos sempre recebem do choque um movimento próprio que eles possuem por força própria, à qual o impulso externo só oferece a ocasião e, por assim dizer, a determinação de operar. ${ }^{14}$

N um segundo nível de análise, porém, tal resposta parece insatisfatória. Embora traga para a Física importantes esclarecimentos nascidos da reflexão metafísica, a teoria da elasticidade não explica qual é o registro próprio da Física. De pouco adianta dizer que a bola de bilhar se move por sua própria força, quando o próprio movimento, enquanto realização exterior da força primitiva, não tem sentido. Ainda que em vez da bola pensássemos em nosso corpo orgânico, o mistério continuaria: como uma metafísica de mônadas inextensas e incomunicáveis pode conviver com uma Física? A verdadeira resposta passa pela reconsideração do fenômeno, ou seja, aquilo que não extrapola o universo perceptivo de cada mônada e nem por isso é ilusório:... para nada adiantar sem necessidade, nós nada faz emos senão pensar, e também nada buscamos para nós senão pensamentos, e os fenômenos são apenas pensamentos. $M$ as como nem todos os nossos pensamentos são eficaz es, nem servem para nos proporcionar outros pensamentos de certa naturez a, e como nos é impossível deafrar o mistério da conexão 
universal dos fenômenos, é preciso atentar, por meio da experiência, àqueles que nos proporcionaram outrora, e eis em que consiste a utilidade dos sentidos e o que se chama ação fora de nós. ${ }^{15}$

M esmo tendo verificado, na correspondência com Arnauld, que os agregados, enquanto tais, não passam de fenômenos e por isso não podem apresentar os átomos formais exigidos pela M etafísica, não podemos renunciar aos fenômenos como objetos da Física. Fazê-lo seria fechar os olhos para o que Leibniz chama de fenômenos bem fundados. É verdade que Leibniz por vezes refere-se ao fenômeno como ao ilusório, mas a ilusão não esgota a fenomenalidade. Tudo que não é simples como as mônadas é obrigatoriamente visto como fenomênico, e mesmo as modificações da substância, por serem variáveis, são fenomênicas. D aí que as forças derivativas estejam necessariamente neste registro: Todas as forças passivas ou ativas (que sejam mortas ou vivas) de que se trata na física são forças derivativas: "A s forças derivativas que nascem da massa e da velocidade são derivativas e pertencem aos agregados ou ao fenômeno, e quando falo de força primitiva subsistente, não entendo a conservação da força motriz total de que tratamos antes, mas a E nteléquia que exprime ao mesmo tempo esta força total e outras coisas mais.." 16. E stas forças são portanto fenomênicas: "V ires derivativas ad phenomena relego" (Id. II, pág. 275).17

É claro que a própria Física talvez fosse desnecessária se conhecêssemos com total distinção os objetos da metafísica, ou seja, as mônadas, mas 0 fato é que isso nos é negado. Como diz A dams: A s mentes humanas são finitas e a marca definitiva das mentes finitas é que não podem conhecer distintamente uma complexidade infinita. D este modo, se ciência é conheamento distinto, o único tipo de dência que é possível, mesmo em prinápio, para os seres humanos terá por objeto imediato uma representação finitamente complexa de uma realidade infinitamente complexa. A o menos nesta medida os objetos do conhedimento científico serão fenômenos ${ }^{18} \mathrm{C}$ om efeito, não percebemos mônadas, mas apenas a expressão fenomênica de nossas relações com elas, expressão que constitui nosso ponto de vista. D eus não nos poderia criar com uma percepção plenamente distinta do real pois isso nos faria outros deuses, o que poria em risco Sua própria condição de ser perfeitíssimo. Daí que a limitação do ponto de vista seja absolutamente essencial.

Leibniz nos diz: D eus, virando, por assim dizer, de todos os lados e maneiras o sistema geral dos fenômenos que julga conveniente produz ir para manifestar a 
sua glória, e observando todos os aspectos do mundo de todas as formas possíveis (porque não existe nenhuma relação que escape à sua onisciênda), faz com que 0 resultado de cada visão do universo, enquanto contemplado de certa maneira, seja uma substância expressando 0 universo segundo este relance, desde que $D$ eus ache conveniente realizar o seu pensamento e produz ir esta substância. ${ }^{19}$ A ntes de mais nada, note-se que Deus não "gira" o sistema de mônadas, mas 0 sistema de fenômenos, tal a essencialidade da fenomenalidade para as criaturas. Se D eus é único, as criaturas finitas necessariamente não 0 são (dados os critérios racionais de perfeição que regem a criação) e por isso coexistem e se relacionam. $M$ as visto que a definição leibniziana de verdade exige a substância como noção completa, estas relações deverão estar inscritas em cada essência individual, não podendo haver duas substâncias com a mesma situação em relação às outras. Por isso, por mais distinta que fosse a percepção de uma mônada, ela nunca perderia 0 caráter fenomênico, já que a situação de cada mônada lhe impõe um ponto de vista próprio. A fenomenalidade é o próprio ponto de vista, é a própria mônada. Daí que D eus deva "modificar" sua onisciência com o giro, única via para, à maneira de um ser finito, ver o todo sem descolarse dele. D onde D eus, em certo sentido, "ver" fenômenos, na medida em que assume um ponto de vista para conhecer sua essência e criá-lo.

Com isso podemos entender por que o fenomenalismo de Leibniz não o transforma em Berkeley. De fato, anota Leibniz ao fim de sua cópia do Tratado sobre os prinápios do conhedimento humano: $\mathrm{H}$ á muito aqui de correto e concordante com minhas opiniões $M$ as expresso por demais paradoxalmente. Pois não é preciso dizer que a matéria é nada; basta dizer que é um fenômeno, como 0 arco-íris, e que não é uma substância, mas resulta de substâncias. $20 \mathrm{Os}$ corpos são fenomênicos, mas não são um nada, e por isso a Física, devidamente fundada na realidade das mônadas, pode trazer um conhecimento verdadeiro e mesmo privilegiado: Você pergunta como a força primitiva é modificada, por exemplo quando o movimento dos graves é acelerado pela queda. R espondo que a modificação da força primitiva que está na própria mônada não pode ser melhor explicada do que expondo como a força derivativa é transformada nos fenômenos. Pois o que é exibido nos fenômenos extensiva e mecanicamente está na M ônada de maneira concentrada e vital. 21

Pelo visto, através da força derivativa os fenômenos desdobram mecanicamente a força primitiva. A pergunta que fica é se isto realmente 
se deixa espelhar na doutrina das mônadas na qual se baseia toda a metafísica leibniziana. O ra, o que nos diz a M onadologia? Que as mônadas são constituídas pelas percepções e pelo apetite que as conduz a novas percepções. 0 que faz portanto a série de percepções que constitui cada indivíduo? Explicita o ser deste indivíduo. De fato, não sendo as mônadas senão percepção e apetição, a série de percepções conduzida pela apetição faz o ser delas. Esta é, aliás, uma das definições leibnizianas de existência. Com efeito, diz Leibniz: Se se examina bem a questão, o únic certo é que nós percebemos, e que percebemos coerentemente, e que ao perceber observamos certa regra. P erceber coerentemente significa que se percebe de modo tal que se pode dar raz ão de tudo e que tudo se pode predizer. A existência consiste nisto: em perceber observando certas leis, pois, do contrário, tudo seria como um sonho. ${ }^{22}$ A ssim, como o fenômeno é um tipo de percepção, não há dúvida de que ele também explicita o ser do indivíduo (...todos os nossos fenômenos, quer dizer, tudo quanto alguma vez pode acontecer-nos, é apenas conseqüência do nosso ser23 ). R esta apenas dizer, para conciliar os textos de Física e os de Metafísica, que a explicitação coerente do indivíduo se dá mecanicamente pela modificação da força primitiva em força derivativa que produz fenômenos regrados pelas leis da Física.

Com isso afasta-se da Física o perigo de ser vista como uma ficção útil. Ao contrário, ela está fundada metafisicamente. $\mathrm{N}$ ão apenas porque seus objetos, os fenômenos, resultam de substâncias, mas também porque necessariamente resultam delas. E mais ainda, a existência delas consiste em desdobrar-se em fenômenos, como aponta a reflexão a respeito das forças primitiva e derivativa. Com este fundamento, não é difícil ver como se aniquilam os temores dos que questionavam o caráter real dos fenômenos coerentes. 0 mesmo critério que regeu a criação, a saber, 0 máximo de ser com o mínimo de hipóteses, rege agora a produção dos fenômenos: primeiro, seria indigno de Deus criar mônadas cujos fenômenos fossem meramente privados: $D$ eus poderia ter dado a cada substância seus fenômenos independentes dos fenômenos das outras, mas dessa maneira ele teria feito, por assim diz er, tantos mundos sem conexão quantas substâncias há. $M$ ais ou menos como quando se diz que, quando se sonha, se está em um mundo à parte, e que se está no mundo comum quando se está desperto. ${ }^{24}$ Segundo, seria igualmente indigno se tais fenômenos fossem arbitrários: $\mathrm{N}$ ão se deve imaginar que estas idéias como a de cor ou de dor sejam arbitrárias e sem relação 
ou conexão natural com suas causas; não é do uso de D eus agir com tão pouca ordem e razão. D iria, antes, que há um tipo de semelhança, não inteira ou por assim dizer in terminis, mas expressiva, ou de relação de ordem. 25

$R$ ecuperada a validade dos fenômenos no interior de um pensamento racionalista como o de Leibniz, é possível voltar agora ao corpo. Se todos os fenômenos são expressões regradas das substâncias, podendo por isso ser enquadrados nas leis da Física (excetuados, evidentemente, os milagres e as ações livres), de outro lado Leibniz não se cansa de afirmar que a mônada exprime privilegiadamente uma certa região da fenomenalidade, o corpo: A ssim, embora cada M ônada criada represente todo 0 universo, representa mais distintamente 0 corpo que lhe está particularmente afeto e de que constitui a Enteléquia; e como esse corpo exprime todo 0 universo, pela conexão de toda a matéria no pleno, a alma representa também todo 0 universo ao representar esse corpo que lhe pertence de modo particular. ${ }^{26}$ Portanto, os critérios de realidade do fenômeno (vividez, congruência, conexão e previsibilidade) devem valer particularmente para o corpo: 0 fenômeno será congruente quando estiver composto de numerosos fenômenos, dos quais se possa dar razão pela relação que guardam uns com os outros, ou por alguma hipótese comum bastante simples A demais será congruente se conserva a relação habitual com outros fenômenos que se nos apresentaram freqüentemente, de modo que as partes do fenômeno tenham a posição, a ordem e os efeitos que tiveram outros fenômenos semelhantes C aso contrário, os fenômenos serão suspeitosos." 27

De posse destes critérios podemos entender melhor a apresentação leibniziana do corpo como agregado:...e cada substância simples ou mônada distinta, que constitui o centro de uma substância composta (por exemplo de um animal) e o prinápio de sua unicidade, está rodeada por uma massa composta de uma infinidade de outras mônadas. E stas constituem o corpo próprio desta mônada central que representa, segundo as afecções deste corpo, como uma espécie de centro, as coisas que estão fora dela.28 Tal infinidade de mônadas deve formar com a mônada dominante um sistema tão coeso quanto o descrito acima para os fenômenos. $\mathrm{N}$ o entanto, al guns problemas se impõem diante desta idéia de agregado. Como algo inextenso, como as mônadas, pode se agregar? Em que consiste esta dominação da mônada central? Certamente a proximidade física não é uma resposta à primeira pergunta, já que o inextenso não fica nem perto nem distante: não há entre mônadas nenhuma proximidade ou distância espacial ou absoluta; e dizer que estão englobadas em 
um ponto ou disseminadas no espaço é empregar certas ficções de nosso espírito, querendo livremente imaginar o que não pode ser concebido. 29

Tal equívoco é sugerido pelo termo "agregado". D e fato, a imagem que ele nos traz à mente é a da composição de um quebra-cabeça onde cada uma das partes é uma mônada. Somadas, elas formariam o corpo. É exatamente isso que Leibniz não pode aceitar: M esmo que um agregado destas substâncias constitua um corpo, ainda assim elas não constituirão à maneira de uma parte, visto que uma parte é sempre homogênea com o todo, do mesmo jeito que pontos não são partes de linhas. $30 \mathrm{U}$ m agregado fenomênico será sempre fenomênico, por mais que se 0 divida. Daí que as unidades reais não possam ser propriamente partes do corpo, embora este resulte delas: F enômenos, portanto, podem ser sempre divididos em fenômenos menores que poderiam aparecer para animais mais sutis, e nunca se chegará aos fenômenos mínimos. $M$ as unidades substanciais não são partes, e sim fundamentos dos fenômen 0 s. 31 Leibniz já alertara que as forças não podem ser compreendidas imaginativamente e esta dificuldade com o termo "agregado" é a prova disso. Embora fenomênico, o corpo resulta da ação de forças e portanto seu vínculo com elas deve ser apreendido exclusivamente pelo entendimento. D este modo, a primeira pergunta (sobre a natureza do agregado) não poderá ser respondida sem 0 auxílio da segunda (sobre a natureza da dominação).

0 que significa então a dominação, dado que já sabemos que ela nada tem a ver com proximidade física (ou melhor, esta última é que é a expressão fenomênica daquela)? D iz o filósofo: A dominação e a subordinação de mônadas, considerada nas próprias mônadas, não consiste em nada senão graus de perfeição. 32 Esta perfeição, por sua vez, deve ser entendida como ação: D iz-se que a criatura atua ex teriormente, na medida em que tem perfeição; e padece a atuação de uma outra na medida em que é imperfeita. $D$ aí podemos apreender que a dominação de uma mônada sobre o agregado que constitui seu corpo próprio se deve ao fato de que ela age privilegiadamente sobre ele, o qual, de sua parte, é predominantemente passivo em relação a ela. M as o que é esta ação em um universo sem influência física entre mônadas? Como não poderia deixar de ser, é através da percepção que esta ação se manifesta. Entenda-se, toda mônada exprime o todo, mas esta expressão pode ser mais ou menos perfeita segundo o grau de distinção envolvido na referida percepção. $D$ onde se a $M$ ônada tiver percepções distintas, atribui-se-Ihe a ação; se confusas, a paixão. 33 
C onclui-se, pois, que o grau de distinção perceptiva da mônada dominante é superior ao daquelas que formam 0 agregado. $M$ as isto basta para delimitar o corpo? U ma resposta possível é a de $R$ ussell: se então, em um certo volume, há uma mônada com percepçoes muito mais daras que o resto, esta mônada pode perceber tudo que acontece neste volume mais claramente do que qualquer das outras. $E$ neste sentido pode ser dominante sobre todas as mônadas em sua viz inhança imediata. ${ }^{34}$

0 que significaria dizer que o corpo é aquilo que a mônada conhece distintamente e que, em contrapartida, não a conhece? Isso seria dizer, primeiro, que a alma conhece distintamente o seu corpo, o que não é totalmente verdadeiro. Como fenômeno, o corpo consiste em uma complexidade infinita, que não pode ser conhecida por um ser finito. $\mathrm{E}$ menos ainda, pelas razões já vistas, podem ser conhecidas as mônadas das quais o corpo resulta. Poder-se-ia retorquir, então, que não se trata de um conhecimento perfeitamente distinto (o que nos é impossível), mas 0 mais perfeito possível dentre um agregado de mônadas. 0 ra, neste caso nada nos impediria de dizer que nosso corpo aumenta ou diminui segundo nosso grau de conhecimento. Portanto, quando é dita agir, a mônada não estaria tendo um corpo, mas estendendo-o a tudo que passa a conhecer mais distintamente. Isto, contudo, seria incompatível com a experiência que cada um tem de seu corpo, e, como vimos, a fenomena lidade não é um caos desregrado.

A questão se ilumina quando vamos ao parágrafo seguinte da $M$ onadologia: uma criatura é mais perfeita do que outra quando nela se encontra a razão a priori do que se passa na outra, e por isso se diz que ela atua sobre a outra. ${ }^{35} \mathrm{~A}$ distinção perceptiva da mônada dominante não é o critério último de ação, perfeição ou dominação. $E$ isso porque ela também é condicionada por outro critério, que é o de ser ou não a razão a priori do que se passa nas mônadas dominadas. $\mathrm{N}$ ão tendo esta razão, a mônada dominada não poderá conhecer distintamente a dominante, ainda que se possa dizer que o corpo expressa privilegiadamente a alma, tanto quanto a alma ao corpo. Da mesma maneira, a superioridade de conhecimento de uma mônada em relação a outra não faz da última obrigatoriamente uma parte do corpo da primeira se esta não contiver a razão de ser da outra.

0 que faz um agregado ser dominado por uma mônada é o mesmo que está por trás da dependência mútua que experimentamos entre a 
alma e o corpo. Ela é mútua justamente porque ambos se entre-expressam, mas sem que a mônada possa tornar-se eventualmente o corpo de seu corpo: a reciprocidade da dependência não implica a reciprocidade da dominação: Pois enquanto a alma tem perfeição e pensamentos distintos, $D$ eus acomodou 0 corpo à alma e fez por antecipação que o corpo fosse levado a ex ealtar as ordens dela; e enquanto a alma é imperfeita e suas percepções são confusas, D eus acomodou a alma ao corpo, de sorte que a alma se deixa inclinar pelas paixões que nascem das representações corporais, 0 que faz 0 mesmo efeito e a mesma aparência que se um dependesse do outro imediatamente e por meio de uma influência física. ${ }^{36} \mathrm{Em}$ relação às outras substâncias, a mônada pode ser ativa ou passiva, conforme as razões que explicam a ação estejam em uma ou outra. E mesmo simultaneamente ativa e passiva, quando as razões que explicam a ação estão parte em uma, parte em outra, de modo que as perfeições e imperfeições estejam misturadas e partilhadas. No caso do corpo, a coisa muda, pois mesmo quando D eus acomoda a alma ao corpo em função das percepções confusas, é sempre em razão da mônada que 0 agregado é pensado. A razão de ser dele está nela, seja em sua manifestação distinta ou confusa, e é por isso que Deus o criou em harmonia com ela. Aliás, ele nem poderia ter sido criado em desarmonia com ela pois então não seria esse corpo, e isso garante que a dominação seja uma via de mão única.

Com isso entendemoso sentido do agregado dominado, mas será que realmente entendemos o corpo? H avíamos visto que há uma força passiva (ou resistência) que garante a realidade da matéria, mas o que constitui o corpo é a força ativa primitiva, desdobrando-se fenomenicamente através da força derivativa. Sem a dupla força, o corpo não passa de um uno por acidente. $M$ as como se dá esta interação entre força passiva $e$ ativa? Como a matéria contínua constitui os agregados corporais? A dificuldade está em que o corpo, enquanto agregado, já é fenomênico, e portanto resulta da força derivativa; ao passo que a pura difusão da resistência não é fenomênica e sequer pode ser divida ou composta, visto que 0 que se divide são os corpos extensos, não a extensão. Q uando se fala de corporalidade, não estamos mais no terreno da matéria primeira (força passiva), mas da matéria segunda, cuja separação do princípio ativo das mônadas é mera abstração. 0 abismo entre o real (matéria primeira) e o fenomênico (matéria segunda) volta a nos incomodar, mesmo após 
termos compreendido como se dá a passagem da força ativa primitiva para a derivativa.

A última esperança recai, todavia, sobre a hipótese de que talvez este novo abismo não seja realmente novo, e que de alguma forma a matéria primeira possa se beneficiar do caminho aberto pela força primitiva. Isto, é claro, se compreendermos que atividade e passividade são dois aspectos do mesmo ser: U ma e outra são a mesma força por sua origem, mas produz iuse na criação uma disjunção originária com inversão de signos; daí nasceu a inérda natural. E sta inversão originária só é devida a uma limitação, limitação necessária em toda naturez a finita, o que reduz a força passiva ou resistente a ser em si mesma apenas uma simples carêndia ou nada. A o mesmo tempo, toda criatura do universo deve, em razão de sua limitação necessária, comportar uma força passiva, ao lado de sua força ativa. E sta força ativa é a forma, prinápio superior sob o qual é subsumida a matéria, que não é senão limite E ste ser finito em que se unem necessariamente atividade e passividade, forma e matéria, realidade e limitação, constitui a mônada ou substância simples. 37

A gora podemos ver que, se a força derivativa é a própria força primitiva em sua manifestação fenomênica, a força passiva também não é outra que a força primitiva, na medida em que, como criatura, é limitada. A ssim como o ponto de vista da mônada é totalizador e infinito, embora limitado pela perspectiva assumida, também a força ativa será infinita (afinal exprimimos o todo), mas limitada pelo que tem de passividade. D e algum modo, é a matéria que individua a forma, porém ela não vem de fora, não se reúne à forma, dado que já estava nela, não sendo senão esta forma vista a partir de suas limitações. Também por isso a força derivativa construirá o agregado (matéria segunda) de acordo com suas limitações, ou seja, de acordo com a matéria primeira. Tudo, porém, permanece no registro espiritual: a matéria primeira é uma força inextensa; a matéria segunda, ou corpo, é uma série de fenômenos que decorrem da força enquanto ela, mesmo limitada, é a razão de ser de outras forças.

Com isso, todo o universo físico desvenda-se como um universo perceptivo e vice-versa. Trata-se de duas dimensões do mesmo real. As forças ativa e passiva são dois aspectos da mesma enteléquia, destacados respectivamente quando o que está em jogo é o grau de distinção ou 0 de confusão das percepções. Esta força primordial corresponde, na estrutura da mônada (análoga à de D eus), à potência. As próprias percepções, 
compondo o universo fenomênico e corporal de cada ponto de vista, correspondem à percepção (ou onisciência, em Deus). E quanto à apetição (ou Vontade Boa, em D eus)? D irei que a volição é o esforço ou a tendência (conatus) em direção ao que se acha bom e contra o que se acha mau, de modo que esta tendência resulta imediatamente da apercepção que se tem disso. .. H á ainda esforços que resultam de percepções insensíveis, de que não se se apercebe, os quais eu prefiro chamar de apetições do que de volições (ainda que haja também apetiçoes aperceptíveis), pois não se chama de ações voluntárias senão aquelas de que podemos nos aperceber e sobre as quais nossa reflexão pode recair quando elas seguem da consideração do bem e do mal.38 0 conatus, ou força derivativa da Física, é a apetição. Por conseguinte, Física e M etafísica mostram-se os dois lados da mesma moeda. E o corpo, se bem compreendemos a necessidade da fenomenalidade, não é senão o próprio ponto de vista que constitui a mônada, mas na sua ordem. Finalmente podemos entender a exigência de que toda mônada tenha um corpo. Se D eus não o tem é porque não tem um ponto de vista, sua onisciência não tendo limites. Já para a mônada criada, cuja criação implica que será a realização de um dos pontos de vista, o corpo é necessário. D eixá-lo seria deixar de ser criatura.

1 LEIBN IZ, 1993, p. 165 - C arta de L eibniz a A rnauld de 30 de abril de 1687.

2 LEIBN IZ, 1993, p. 145 - C arta de L eibniz a A rnauld de 8 de dez embro de 1686.

3 LEIBN IZ, 1991, pág. 124 - n. 2.

4 A M onadologia , § 72. In LEIBN IZ, 1979, pág. 113.

5 Exame da Física de D escartes. In LEIBN IZ, 1982, pág. 435.

6 Id., pág. 436.

${ }^{7}$ A R eforma da F ilosofia Primeira e a noção de substância. In: LEIBN IZ, 1982, pág. 457.

8 Sobre a própria naturez a, ou seja, sobre a força ínsita e as açoes das criaturas, para confirmar e ilustrar sua dinâmica. In: LEIBN IZ, 1982, pág. 490.

9 LEIBN IZ, 1996, II, iii,p. 333.

10 E xame da Física de D escartes. In: LEIBN IZ, 1982, pág. 437.

11 Id., p. 438.

doispontos, Curitiba, São Carlos, vol. 2, n. 1, p.83-99, outubro, 2005 


\section{8}

12 C arta a Burcher D eVolder de 21 de janeiro de 1704. A pud ADAM S, 1993, p. 379.

13 Exame da Física de D escartes. In: LEIBN IZ, 1982, p. 439.

14 Id., p. 440.

15 LEBN IZ, 1993, p. 139.

16 LEIBN IZ, 1996,V. III, p. 251.

17 GUEROU LT, 1934, p. 186.

18 ADAM S, 1993, p. 228.

19 D iscurso de M etafísica, artigo 14. In: LEIBN IZ, 1979, p. 130.

20 A pud ADAM S, 1993, p. 224.

21 C arta a W olff de 9 de julho de 1711, apud ADAM S, 1993, p. 385.

22 Sobre a existência, os sonhos e o espaço. In: LEIBN IZ, 1982, p. 145.

23 D iscurso de M etafísica, artigo 14. In: LEIBN IZ, 1979, p. 130.

24 E sclaredmento das dificuldades encontradas por B ayle no Sistema novo da união da alma e do corpo. In: LEIBNIZ, 2002, p. 65.

25 LEIBN IZ, 1966, II, viii, p. 109.

${ }^{26}$ A M onadologia, § 62. In: LEIBN IZ, 1979, p. 111.

27 Sobre o modo de distinguir os fenômenos reais dos imagi nários. In: LEIBN IZ, 1982, p. 266.

28 P rinápios da N atureza e da G raça fundados em raz ão. In: LEIBN IZ, 1982, p. 598.

${ }^{29} \mathrm{C}$ arta a $\mathrm{D}$ es B osses de 16 de junho de 1712. A pud B elaval, Y. Leibniz. Initiation à sa philosophie. Paris, V rin, 1993, p. 222.

30 p hilosophical E ssays. Indianápolis, H ackett, 1989, pág. 105, apud A DAM S, 1993, p. 243.

31 Philosophical Papers and L etters. D ordrecht-Boston, R eidel, 1969, pág.536, apud A DAM S, 1993, p. 243.

32 C arta a D es B osses de 16 de junho de 1712. A pud ADAM S, 1993, p. 285.

33 A M onadologia, § 49. In LEIBN IZ, 1979, p. 110.

34 RU SSELL, 1937, p. 148

35 A M onadologia, § 50. In LEIBN IZ, 1979, p. 110.

36 LEIBN IZ, 1969, § 66, p. 140.

37 G ueroult, pág. 169.

38 LEIBN IZ, 1996, II, xxi, p. 146.

doispontos, Curitiba, São C arlos, vol. 2, n. 1, p.83-99, outubro, 2005 


\section{Referências bibliográficas}

LEIBN IZ, G.W. 1979. C oleção 0 s P ensadores. São Paulo: A bril Cultural.

LEIBN IZ, G.W. 1996. D ie Philosophischen Schriften. Ed. C. I. Gerhardt, Vol. I - VII. H ildesheim: G eorg O ImsVerlag.

LEIBN IZ, G. W. 1993. D iscours de M étaphysique et C orrespondance avec A rnauld. Ed. G. Grua. Paris:Vrin.

LEIB N IZ, G.W. 1982. E scritos Filosóficos. Ed. e trad: O LASO, E. Buenos Aires: Editorial Charcas.

LEIBN IZ, G.W. 1969. E ssais deT héodicée. Paris: Garnier-Flammarion.

LEIBN IZ, G.W. 1991. La M onadologie. Paris: Librairie Genérale Française.

LEIBN IZ, G.W. 1966. N ouveaux E ssais sur l'E ntendement H umain. Paris: Garnier-Flammarion.

LEIBN IZ, G.W. 2002. Sistema N ovo da naturez a e da comunicação das substâncias, e outros textos. Trad. E. M arques. B elo H orizonte: Editora UFMG.

ADAM S, R .M . 1993. L eibniz. D eterminist, Theist, I dealist. N ew YorkO xford: 0 xford U niversity Press.

BELAVAL,Y. 1976. É tudes L eibniz iennes. Paris: Gallimard. . 1993. L eibniz. Initiation à sa P hilosophie. Paris, V rin, 1993. L eibniz critique de D escartes. Paris, G allimard, 1960.

GAR BER , D. 1980. EI Espacio como R elation en L eibniz. C aracas: Equinoccio.

GU ER O U LT, M . 1934. D ynamique et M étaphysique leibniziennes. Paris: Belles Lettres.

R USSELL, B. 1937. A critical Exposition of the Philosophy of Leibniz. Londres: Allen and U nwin. 
४४ 